\title{
Entrevista
}

Maria de la Paz, Maripaz Jaramillo, es una de las principales representantes del movimiento expresionista colombiano. Egresada de la Escuela de Bellas Artes de la Universidad de los Andes y dueña de un estilo pictórico inconfundible, es una convencida de que el arte debe salir de los recintos privilegiados y convertirse en un medio de realización y de reconciliación para todos. Un puente hacia la felicidad cuyos cimientos se levantan en la escuela.

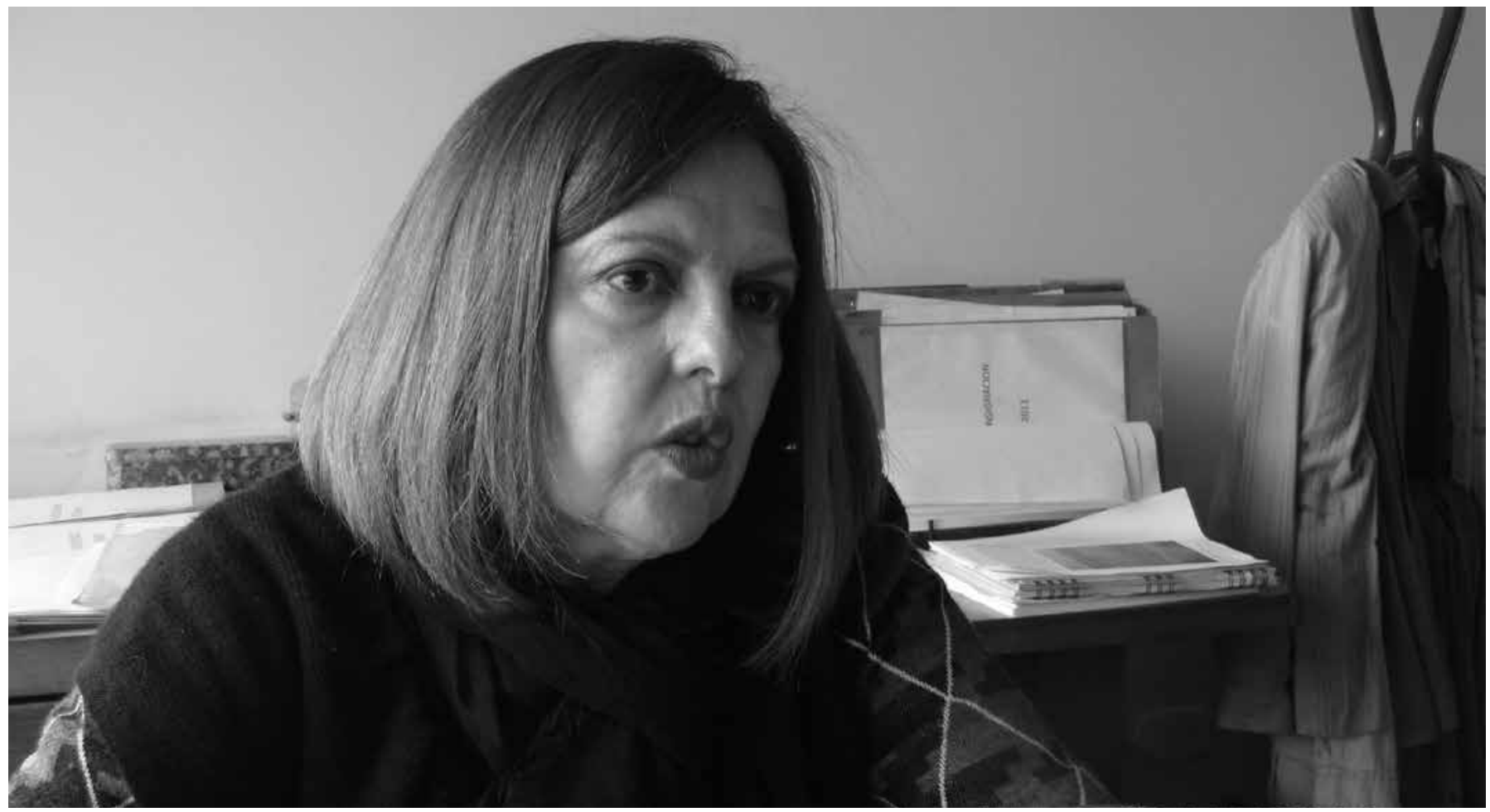

\section{El arte como recreación del presente}

Entrevista con Maripaz Jaramillo

Por: Sandra Patricia Ordóñez Castro 


\section{Sandra Patricia Ordoñez: ¿Cuándo descubriste tu vocación artística?}

Maripaz Jaramillo: Yo creo que desde niña. Recuerdo mi niñez con una gran alegría, porque lo pasé muy bien y me hicieron un ambiente muy interesante en la casa. Imagínate que el que pintaba en mi casa era mi hermano mayor y a él le compraban los óleos y todas las cosas. Él pintaba con Luis Caballero en la casa cuando estaban en el colegio, y yo lo que hacía era que me metía allá y les revolvía los colores. Esa fue mi primera acción con la pintura. Y desde ahí empieza mi amor por ella y esa inquietud de querer ser pintora.

\section{S.P.O.: ¿Por qué te expulsaban de los colegios?}

M.J.: Es que eran unos colegios muy estrictos. Hay un estudio que hizo García Márquez sobre gente que se ha destacado, y resulta que la mayoría de la gente que se había destacado, la habían echado del colegio. Porque eran ambientes muy estrictos en donde no se entendía la forma de ser de uno. Entonces yo era muy necia y muy... fuerte...Y esa fue la razón por la que me echaron de dos colegios.

S.P.O.: ¿Cómo fue el tránsito al ámbito universitario?

M.J.: Bueno, para mí fue muy importante la universidad porque en esa época tenían maravillosos profesores. Estaba Antonio Roda, Santiago Cárdenas, Umberto Giangrandi... entonces teníamos un grupo muy bueno de artistas y eso me ayudó mucho. Así como fui tan mala estudiante en el colegio, en la universidad fui buena (mi tesis fue laureada). Yo creo que allá cambió todo, fundamentalmente, porque en eso, en el arte, yo sí estaba muy interesada...

\section{S.P.O.: ¿Cómo describirías tu estilo pictórico?}

M.J.: Yo creo que tiene mucho de expresionismo y tiene mucho de pop. Están metidas esas dos líneas. El expresionismo con la forma del dibujo, que no es un dibujo exacto, no es un retrato, es muy expresionista. Y el pop, porque está muy basado en lo popular, en lo que sucede continuamente, en todas la actualidad del país. Yo creo que ahí entra el pop a funcionar muy bien.

S.P.O.: Dentro de eso ha sido muy importante y muy característico tuyo el manejo del color. ..

M.J.: Sí. El color siempre ha sido para mí muy importante. La academia dice que uno debe trabajar con colores afines, pero yo siempre trabajo con colores contrastantes. Mi paleta está llena de colores fuertes, ácidos... Allí radica gran parte de la fuerza de mi trabajo: con este manejo del color se logra un impacto importante dentro de la obra.

\section{S.P.O.: ¿Qué lugar tiene la pintura en tu vida?}

M.J.: Llevo cuarenta años trabajando y siempre he estado muy interesada en el tema de la pintura. No he dejado de pintar ni un solo año, ni meses. Siempre estoy trabajando. Y eso lo hace tan importante para mi vida. Siempre he estado muy metida dentro de mi pintura y siempre he estado muy disciplinada trabajando. La pintura es mi vida, es mi forma

\section{S.P.O.: ¿Cómo es tu proceso creativo?}

M.J.: Yo no soy como otros artistas que dejan de pintar por tiempos, porque no les llega la musa. Yo trabajo todos los días con un horario que es casi de oficina: de 9 a 1 y de 3 a 6 (por la noche no trabajo casi porque el color se distorsiona con las luces). Y como siempre estoy trabajando por series, primero hago un estudio sobre la serie que voy a trabajar y eso hace que sea "más fácil" poder pintar después. Recorto fotos de revistas, periódicos, veo la televisión y a través de todo eso enriquezco el concepto y puedo luego entrar en el proceso concreto de creación con relativa fluidez.

S.P.O.: ¿De alguna manera podríamos hablar entonces de una integración multimedia que atraviesa tu obra, desde el proceso mismo de su concepción... una re-asimilación de las imágenes que ofrece el mundo mediático?

M.J.: Sí. Eso es muy importante. Mi obra se alimenta de todas las imágenes que ofrece el mundo como discurso sobre sí mismo. Y por eso, otra cosa que considero característica de mi obra es el sentido del humor. Me gusta que al ver la obra la gente se sonría, se sienta agradada y por eso el humor es algo muy importante dentro de mi obra.

S.P.O.: Sentido del humor que en algunas ocasiones ha sido interpretado como sátira...

M.J.: Sí. Pero eso responde más a una interpretación. Por ejemplo cuando hice las reinas de belleza, la gente pensó que yo me estaba burlando de los reinados. Pues claro que me siento un poquito afectada por cómo tratan a estas niñas en los reinados, pero lo que hice fue ponerle humor al momento del reinado en una aproximación espontánea, bastante desprejuiciada. Lo lindo es que en el arte tú puedes tener tu discurso, pero luego la gente ve la obra y elabora sus discursos propios y hace sus propias aproximaciones. 


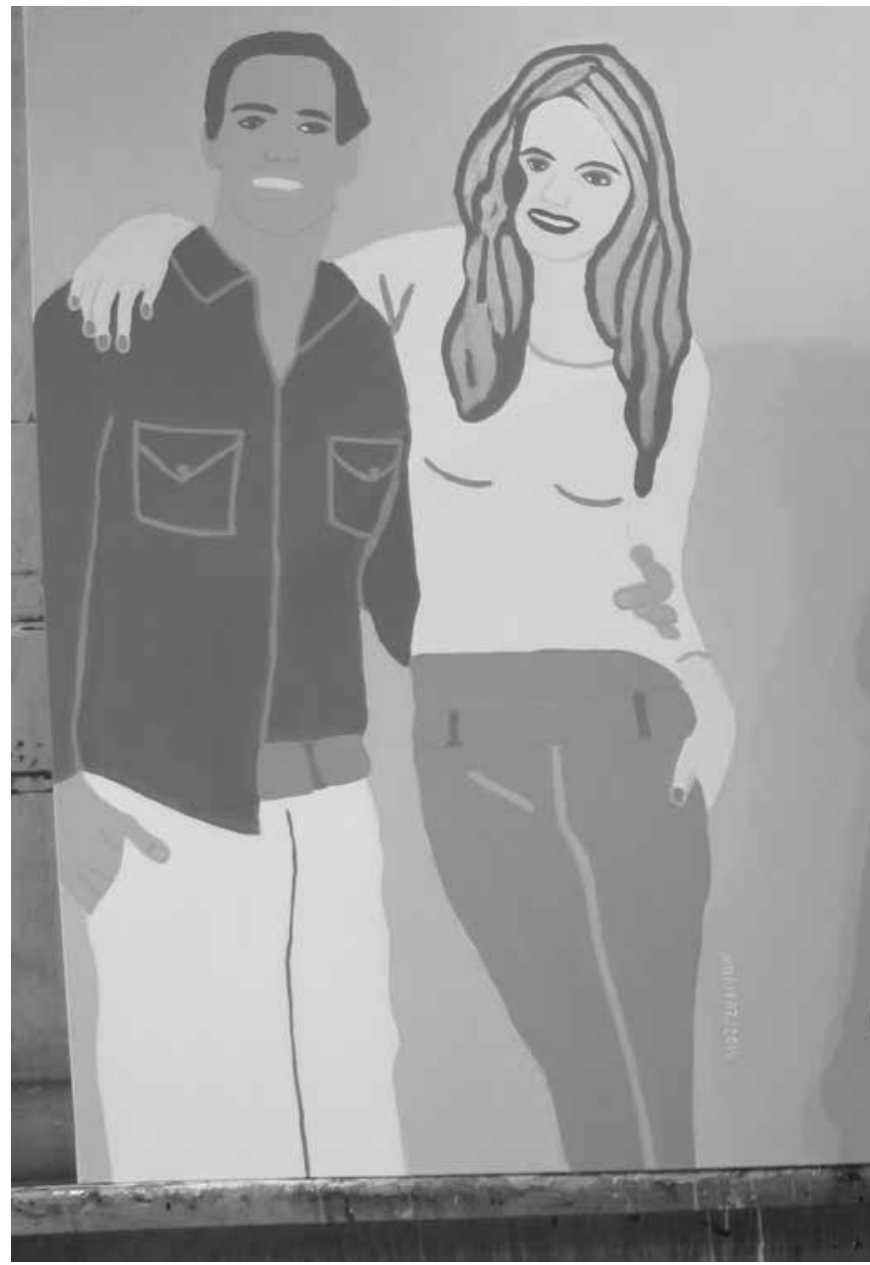

S.P.O.: ¿Cuál es tu perspectiva de la realidad cuando pintas? M.J.: Mi obra siempre está referida a la realidad y a la actualidad en particular. Yo siempre he trabajado mirando revistas, mirando el periódico, mirando los noticieros... siempre estoy muy informada para ver la realidad de lo que está sucediendo y de eso se trata mi obra. Pero al mismo tiempo mi trabajo supone una mirada personal de esa realidad... Por ejemplo, en alguna oportunidad hice una serie muy interesante que se llama Diciembre en Cartagena, en la que mostraba cómo Cartagena se estaba deteriorando, sin que eso fuera precisamente un tópico en cada cuadro. El asunto es que de alguna manera la realidad siempre está presente, y diría que en todas mis series hay un poquito de denuncia. No pienso que la mía sea una obra política como la de Beatriz González, pero sí está muy metida dentro de la realidad del país.

\section{S.P.O.: ¿Consideras que el arte tiene una responsabilidad social?}

M.J.: Pues sí. Yo sí creo que el arte tiene una responsabilidad social. Pero hay artistas que trabajan otras cosas, como el arte abstracto, otro tipo de cosas que también son muy válidas dentro de la historia del arte colombiano. Sin embrago, ese vínculo con la sociedad y con la actualidad es lo que hace que sea interesante lo que yo hago.

S.P.O.: Hay temas recurrentes en tu trabajo, como por ejemplo, la mujer...

M.J.: Sí. Sin que yo sea feminista, el tema de las mujeres ha sido muy importante para mí. En estos cuarenta años, me he aproximado a la mujer en diferentes formas. He trabajado el maltrato a la mujer y cómo la mujer ha surgido en estos últimos años y ha ido ocupando un lugar diferente en la sociedad. En este momento no se puede decir que estamos divinamente, pero sí creo que hemos avanzado muchísimo, y ustedes, las jóvenes, están haciendo una labor muy importante para la que nosotros abrimos el camino. La mujer joven ya mira la vida y su trabajo de una forma diferente. A nosotras nos tocó una lucha grande para lograr el reconocimiento... por ejemplo, ahora hay muchas pintoras, pero antes no había tantas... lograr reconocimiento en ese ámbito implicaba mucha lucha y mucha consagración.

S.P.O.: Sin embargo, tú lograste ya desde tus primeros años de estudiante incursionar en los espacios reservados para los grandes de la pintura ¿A qué atribuyes ese éxito?

M.J.: Sí. No me puedo quejar. Siempre tuve bastante reconocimiento. Cuando estaba en la universidad, siendo muy joven, me gané el Salón Nacional. Y desde ahí empezó a funcionar conmigo una forma muy interesante de reconocimiento y de aceptación. Y eso que era una obra diferente, porque en esa época existían muy buenos dibujantes, como David Manzur, Luis Caballero, los maestros Santiago y Juan Cárdenas... Yo no soy excelente dibujante, sino que soy muy expresionista y ahí creo que se libró una gran lucha que le abrió camino a muchos otros artistas jóvenes que trabajaron en mi línea. Pero siempre tuve mucha acogida y tuve con los críticos de arte muy buena relación. 
S.P.O.: Pero más allá de los críticos de arte, llama la atención la acogida del público en general. ¿Crees que esta influencia pop de la que hablábamos hace un rato, el manejo del color, el tipo de imagen que presentas en tu obra conecta más con la sensibilidad de la gente del común?

M.J.: Pues, creo que mi obra no es tan difícil de entender. Mi obra se entiende fácilmente y como yo trabajo las series de la actualidad, entonces la gente se conecta más rápido porque se trata de lo que está pasando en ese momento. Creo que por eso el público me ha reconocido y ha tenido las ganas de tener mi obra. Eso ha sido para mí muy importante en estos cuarenta años de trabajo.

S.P.O.: Cuarenta años de labor ininterrumpida, suponen una fuente inagotable de energía creativa. ¿De dónde surge todo ese potencial de creación?

M.J.: Creo que es esa comunicación tan importante con el público. A la gente le gusta mucho la obra, los colores... y eso es muy gratificante... es como un motor. El ser bien recibido y el ser aceptado le da a uno una energía muy grande para seguir adelante.

S.P.O.: ¿Tienes alguna anécdota de grata recordación en cuanto a esa retroalimentación del público que tanto valoras?

M.J.: Sí. Una de las experiencias bonitas en ese sentido fue que una vez alguien me dijo - iQué linda esa obra que usted hace y qué rico poderla tocar! Eso fue para mí muy sorpresivo porque yo no había pensado en esa posibilidad... pero eso me impulsó a hacer escultura. Entonces hice esculturas de las mujeres en fibra de vidrio y en la exposición, donde siempre dice "no tocar", yo ponía "Por favor, tocar". Para mí siempre ha sido muy importante lo que diga el público. Bueno, también es importante lo que digan los críticos, pero lo que la gente dice apenas ve mi obra, eso es muy importante para mí.

S.P.O.: ¿Hay alguna serie que recuerdes con especial cariño? M.J.: Bueno, creo que la serie de la Salsa marcó muchísimo. Lo mismo que la serie de los Oficios de la mujer. Fueron series que a la gente le gustaron mucho y que por lo mismo marcaron mi carrera. Otra serie que fue interesante fue la de las mariposas, durante la época de Pablo Escobar... como la mariposa tiene una vida muy efímera, en esa época yo decidí hacer esa serie viendo lo que estaba sucediendo en el país. Podría pensarse que unas mariposas no tienen nada qué ver con Pablo Escobar, pero la expresión de la vida tan corta y tan bella de una mariposa implica una perspectiva de lo social en ese momento de nuestra historia.

S.P.O.: ¿Podríamos decir entonces que durante los estudios preliminares de las series, se va fraguando un concepto, una especie de síntesis personal del aspecto de la realidad sobre el cual se está trabajando, que es el que finalmente da forma a tu obra?

M.J.: Sí, claro. Eso es muy importante. Como en el caso de la serie en la que estoy trabajando ahora que es la serie de los Abrazos. Esta serie tiene mucho que ver con lo que está pasando en este momento con el proceso de paz. Una vez más, si tú miras la obra, no vas a decir "Sí, se trata del proceso de paz...". No tiene nada que ver con los guerrilleros, ni con la conversación de Cuba. Sin embargo, el vínculo está en el concepto de la reconciliación.

S.P.O.: Y claramente la serie Abrazos es muy representativa de tu estilo y línea de trabajo habitual. La serie de las Mariposas, por otra parte, fue algo más bien excepcional en cuanto a la forma.

M.J.: Sí. Lo mismo que la serie del agua. Aunque partían del mismo principio, como de síntesis de un asunto cotidiano que nos afecta a todos, fueron series distintas y por lo mismo, más o menos aceptadas: la gente se quedaba medio desconcertada y como que decían "Esto no puede ser de María de la Paz Jaramillo", pero así lo hice porque son momentos que necesito, de cambio, que después me permiten volver a la fuente.

S.P.O.: Estas series que dices que desconcertaban a la gente, tuvieron, sin embargo, mucha acogida en países como la India...

M.J.: Sí. En la India la mariposa es símbolo de paz y de amor. Aquí también ya está un poco de moda eso, pero allá ha sido tradicional que cuando la gente se casa, votan una cantidad de mariposas al aire... Entonces hicimos una exposición que fue a la India, a Turquía, a Egipto y tuvo mucha aceptación. En primer lugar porque en esos países, por preceptos religiosos recientes no se podía presentar la figura humana en el arte. Por eso llevamos la serie de las mariposas con la cancillería y gustó muchísimo. 
S.P.O.: ¿Podría ser entonces este un llamado de alerta a las escuelas en cuanto a no permitir que se pierdan esas bases fundamentales de la formación artística en aras de la innovación del discurso estético?

M.J.: Pues sí. Yo sí creo que sería bien importante poder decirle a las escuelas que no dejen de enseñarle a los artistas la forma básica de dibujo, de pintura, de grabado, que es muy importante. Después los artistas pueden hacer todo lo demás que quieran. Pero que dentro de la formación deben tener todo eso que a veces ha desaparecido de los pensum de las universidades.

S.P.O.: ¿Qué puedes decirnos de tu producción en el terreno del "arte utilitario"?

M.J.: Desde el principio de mi carrera, siempre trabajé arte utilitario, porque me parece importante, por una parte, trabajar en el diseño de cosas contemporáneas, y por otra, que la gente joven pueda adquirir estos objetos. Porque son objetos que no son caros, que la gente joven puede tener y utilizar: individuales, camisetas, carteras. Yo me adelanté un poco a eso, porque ya en este momento, por ejemplo en la Luis Ángel Arango tienen un almacén con objetos de artistas colombianos, lo mismo que en el Museo Nacional, en la Galería Garcés, etc., lo cual denota que ya estamos progresando también en ese tema. A mí al comienzo me decían que era una comerciante, que cómo así que haciendo individuales y carteras, que ¿qué era eso? pero eso también entró dentro del mundo del arte y es algo que considero también muy importante dentro de mi obra.

S.P.O.: ¿Podría esto llegar a convertirse en una tendencia, en el sentido de que el arte comience a salir de los espacios privilegiados como los museos y las galerías, para entrar a formar parte de la vida cotidiana de las personas del común?

M.J.: Sí, creo que es muy posible. Y es la razón por la cual yo he hecho todos estos objetos. Ya hay muchos espacios, se está llegando a más lugares y la gente puede obtener y hacer uso del arte. Eso me parece bellísimo y es síntoma de vitalidad del arte y de la sociedad, ambas integradas en perfecta armonía.
S.P.O.: ¿Dirías que el arte tiene un papel relevante en el desarrollo del ser humano?

M.J.: Bueno, yo soy jurado de una propuesta de la Fundación BAT, donde se trabaja con gente que no ha estudiado arte, pero que hace arte. Eso es muy interesante porque uno ve cómo el arte es un medio de realización para la gente, ya sea un artista como yo, que soy formada en la universidad y después en posgrado y todo eso, o también estos otros artistas de los que te hablo, que sin una formación formal, encuentran en el arte un medio para expresarse con resultados sumamente interesantes.

S.P.O.: ¿Crees en el arte como factor de humanización de la escuela, un poco en contravía de ese carácter restrictivo que tú debiste afrontar durante tu paso por la educación básica?

M.J.: Sí. Y creo que por fortuna cada vez se tiene más consciencia de eso. A los niños, ya desde muy chiquitos los introducen a la pintura. Ese carácter de restricción ha cambiado bastante. No en todos los colegios, pero sí muchos se han abierto a nuevos temas y al arte, no sólo la pintura, sino también la literatura y la música, y a través de esta aproximación, los niños chiquitos y adolescentes se pueden realizar mucho más. Otra cosa es que cuando yo estudié en la Universidad de los Andes solamente había un hombre dentro de la escuela de Bellas Artes. En este momento en las escuelas de arte hay muchos hombres también. Y eso tiene que ver con un cambio de mentalidad desde la educación en los colegios y de los padres también, que ya no solamente están pensando en tener abogados y médicos, sino, fundamentalmente, personas felices.

S.P.O.: Ya a manera de coda y en presencia de la serie de Abrazos que se encuentra en proceso, ¿crees en el arte como medio de reconciliación?

M.J.: Sí, por supuesto. El arte entra en contacto directo con la sensibilidad de la gente y moviliza. Por eso a través del arte se puede generar una disposición general hacia la concordia. A través del arte se puede ser feliz, pero se puede también aproximar a los demás a su propio universo de felicidad. 